\title{
Structural and Magnetic Properties of LiZnO Added $\mathrm{MgFe}_{2} \mathrm{O}_{4}$ Composite
}

\author{
Ravindar Tadi ${ }^{1,2}$, Yong-Il Kim ${ }^{2}$, CheolGi Kim ${ }^{1}$, and Kwon-Sang Ryu ${ }^{2 *}$ \\ ${ }^{I}$ Department of Materials Science and Engineering, Chungnam National University, Daejeon 305-764, Korea \\ ${ }^{2}$ Korea Research Institute of Standards and Science, Daejeon 305-340, Korea
}

(Received 17 September 2010, Received in final form 5 October 2010, Accepted 6 October 2010)

\begin{abstract}
$\mathrm{Li}_{0.1} \mathrm{Zn}_{0.9} \mathrm{O}$ and $\mathrm{MgFe}_{2} \mathrm{O}_{4}$ powders were synthesized using chemical methods and mixed in different proportions to prepare a mixture of $\mathrm{Li}_{0.1} \mathrm{Zn}_{0.9} \mathrm{O}$ and $\mathrm{MgFe}_{2} \mathrm{O}_{4}$ that was thermally treated between 900 to $1100^{\circ} \mathrm{C}$ for 1 hour. Structural characterization was done using $\mathrm{X}$-ray powder diffraction measurements. Grain sizes and morphologies of $\mathrm{Li}_{0.1} \mathrm{Zn}_{0.9} \mathrm{O}, \mathrm{MgFe}_{2} \mathrm{O}_{4}$, and $\mathrm{Li}_{0.1} \mathrm{Zn}_{0.9} \mathrm{O}+\mathrm{MgFe}_{2} \mathrm{O}_{4}$ samples were observed using a scanning electron microscope. Variation of magnetic properties of the $\mathrm{Li}_{0.1} \mathrm{Zn}_{0.9} \mathrm{O}+\mathrm{MgFe}_{2} \mathrm{O}_{4}$ samples due to the addition of $\mathrm{Li}_{0.1} \mathrm{Zn}_{0.9} \mathrm{O}$ was studied in relation to the structural changes occurring due to the thermal treatment. In particular, changes in the cationic distribution between the tetrahedral and octahedral positions were studied with respect to the increase of the annealing temperature. Magnetization was found to be dependent on the cations distributed in the tetrahedral and octahedral sites of the $\mathrm{MgFe}_{2} \mathrm{O}_{4}$.
\end{abstract}

Keywords : multiferroic composites, structure, inverse spinels, magnetostrictive, piezoelectric

\section{Introduction}

Multiferroic materials are a distinctive class of materials in which magnetization can be possible without application of a magnetic field and electric polarization can be possible in the presence of a magnetic field [1,2]. Multiferroic coupling among the ferromagnetic and ferroelectric phases has potential applications in sensing, data storage, and multifunctional areas [2,3]. Multiferroic materials are of two types, single phase and composite systems. However, in single phase multiferroic materials, a weak coupling at low temperatures has been a major disadvantage. In order to overcome this problem, composite materials that contain magnetostrictive and piezoelectric phases were employed [1-6]. Application of an electric field generates a piezoelectric effect leading to the mediation of stress and strain by the magnetostriction of the magnetic phase and, in turn, magnetization is possible $[5,6]$.

$\mathrm{MgFe}_{2} \mathrm{O}_{4}$ is a soft magnetic material with a cubic spinel structure and has the advantage of its magnetic characteristics being controllable over a wide range by addition of suitable transitional elements [7]. $\mathrm{MgFe}_{2} \mathrm{O}_{4}$ consists of tetrahedral and octahedral sites and is denoted by $\left(\mathrm{Mg}_{1-\mathrm{x}}-\right.$ $\left.\mathrm{Fe}_{\mathrm{x}}\right)\left[\mathrm{Mg}_{\mathrm{x}} \mathrm{Fe}_{2-\mathrm{x}}\right] \mathrm{O}_{4}$; ' $\mathrm{x}$ ' is called the degree of inversion

*Corresponding author: Tel: +82-42-868-5164

Fax: +82-42-868-5018, e-mail: ryuks@kriss.re.kr which largely depends on the material system and the experimental conditions used [8]. Magnetization as well as magnetostriction can be modified in these spinels which can be utilized to synthesize multiferroic materials.

Zinc oxide with self assembling and piezoelectric properties is suitable for the fabrication of multiferroic composites [9]. Oxidation of zinc can be controlled to synthesize nano size materials with different shapes and appropriate piezoelectric coefficients [9]. Substitution of $\mathrm{Li}$ in $\mathrm{ZnO}$ with a smaller radius generates a ferroelectric property and combination of $\mathrm{LiZnO}$ and $\mathrm{MgFe}_{2} \mathrm{O}_{4}$ may be a possible multiferroic composite [10]. In spite of the lack of reports on the $\mathrm{LiZnO}+\mathrm{MgFe}_{2} \mathrm{O}_{4}(\mathrm{LZO}+\mathrm{MFO})$ material system and when considering the possibility of potential applications in the field of multiferroics, we tried to focus on finding the effect that LiZnO has on the changes caused in the structure and soft magnetic properties in the synthesized composites that utilize nano powders.

\section{Experimental}

$\mathrm{MgFe}_{2} \mathrm{O}_{4}$ was synthesized using the thermal decomposition of oxalates obtained using a blend of magnesium and iron nitrates. Appropriate quantities of magnesium nitrate, iron nitrate, and oxalic acid (Sigma Aldrich, 99.99 $\%$ ) were dissolved in ethanol, dried, and thermally treated at $500{ }^{\circ} \mathrm{C}$. The brownish substances were powdered [7]. 
Li substituted Zinc oxide was synthesized with zinc nitrate hexahydrate, lithium nitrate, and oxalic acid (Sigma Aldrich, 99.99\%) by dispersion in ethanol and drying followed by thermal treatment. These $\mathrm{MgFe}_{2} \mathrm{O}_{4}$ and $\mathrm{Li}_{0.1} \mathrm{Zn}_{0.9} \mathrm{O}$ were mixed with suitable weight percents, milled and pelletized with a pressure of $50 \mathrm{Mpa}$, and thermally annealed at a temperature in the range of 900 to $1100^{\circ} \mathrm{C}$ for $1 \mathrm{~h}$. Structural properties were measured using an X-ray diffractometer (Rigaku, Japan, $\mathrm{Cu}_{\alpha}$ ). The microstructure was observed using a field emission scanning electron microscope (FE SEM, Holland). Magnetic properties were recorded using a vibrating sample magnetometer (VSM, Lakeshore, USA) after calibration with a nickel standard sample.

\section{Results and Discussion}

Fig. 1 shows the $\mathrm{X}$-ray diffraction patterns of the pure $\mathrm{MgFe}_{2} \mathrm{O}_{4}, \mathrm{Li}_{0.1} \mathrm{Zn}_{0.9} \mathrm{O}$, and $\mathrm{Li}_{0.1} \mathrm{Zn}_{0.9} \mathrm{O}+\mathrm{MgFe}_{2} \mathrm{O}_{4}$ samples. Substitution of $\mathrm{Li}$ in $\mathrm{ZnO}$ was confirmed by the peak shift of $\mathrm{Li}$ substituted $\mathrm{ZnO}$ towards a lower angle as shown in the inset figure of Fig. 1 [11]. Phase identification was confirmed by comparison with the international centre for diffraction data base (ICDD) powder diffraction file (PDF) No.36-1451 for $\mathrm{MgFe}_{2} \mathrm{O}_{4}$, PDF No. 88-1943 for $\mathrm{ZnO}$, and as a combination of both of these phases for composite samples. It is also evident from Fig. 1, diffraction intensities of (311) for $\mathrm{MgFe}_{2} \mathrm{O}_{4}$ and (101) for $\mathrm{ZnO}$ were present in the LZO+MFO samples. Intensities of the corresponding peaks were closely related with the number of cations present in the tetrahedral and octahedral sites in

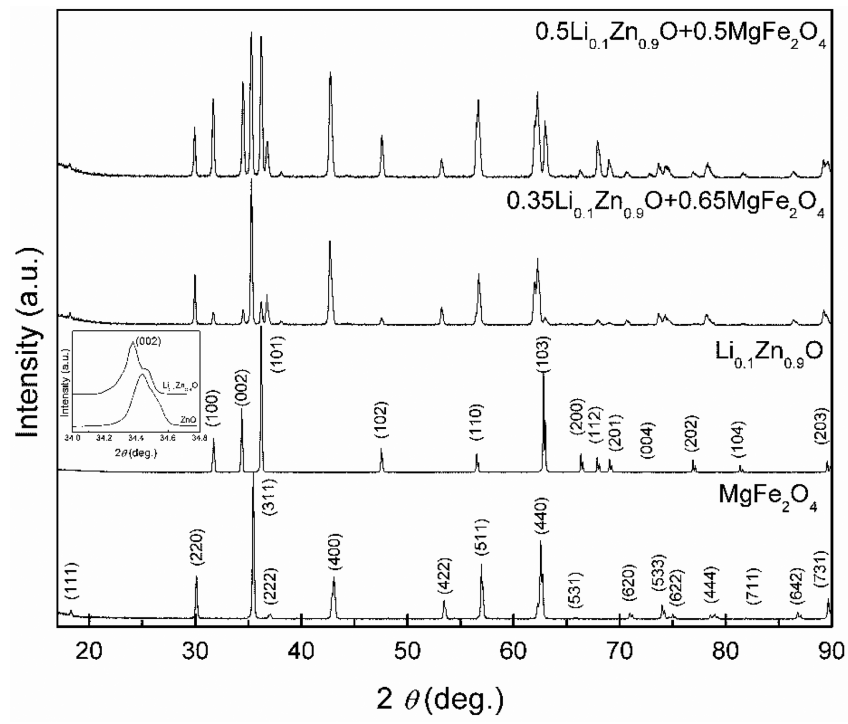

Fig. 1. X-ray diffraction patterns of Pure $\mathrm{MgFe}_{2} \mathrm{O}_{4}, \mathrm{Li}_{0.1} \mathrm{Zn}_{0.9} \mathrm{O}$ and $\mathrm{Li}_{0.1} \mathrm{Zn}_{0.9} \mathrm{O}+\mathrm{MgFe}_{2} \mathrm{O}_{4}$ samples.

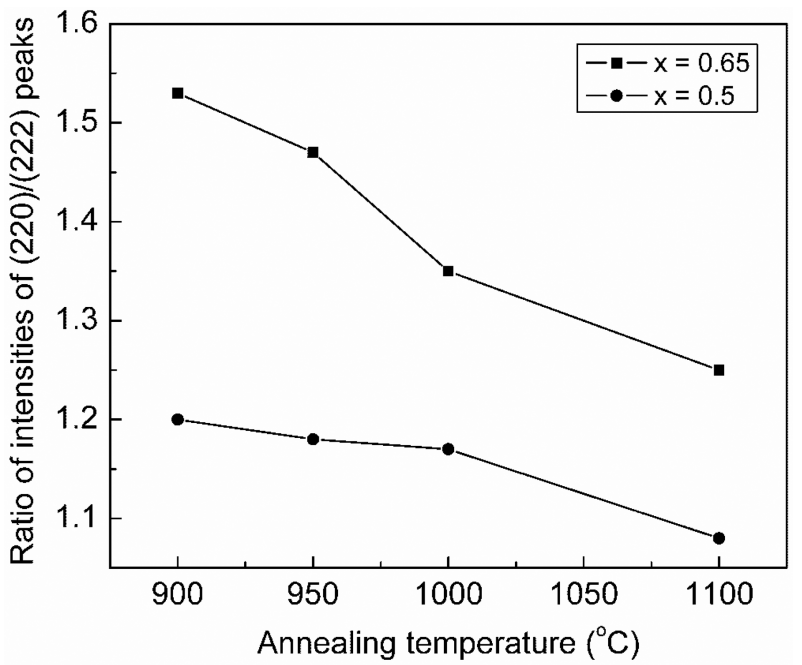

Fig. 2. Ratios of relative intensities of $(220) /(222)$ diffraction lines for $(1-x) \mathrm{Li}_{0.1} \mathrm{Zn}_{0.9} \mathrm{O}+(x)[x=0.5,0.65]$ samples annealed from 900 to $1100^{\circ} \mathrm{C}$ for $1 \mathrm{~h}$.

the spinels [12]. Weak (111) and strong (220) peaks indicate an inverse type spinel for the present samples [13]. The intensity of (220) depends on the cations present in the tetrahedral sites and the intensity of (222) was related to the cations in the octahedral sites [12]. In order to find the relation between magnetic ions and the magnetization, ratios of the relative intensities of the (220) and (222) lines were calculated and plotted as shown in Fig. 2. Variation in the ratios of the peak intensities suggests the possibility of transport of cations among the polyhedral sites (Fig. 2).

Microstructure and density were found to have tremendous effects on the material properties and were significantly influenced by the thermal treatment. Densities were calculated from the weight and volume of the pillets. Photographs of the microstructure of pure $\mathrm{MgFe}_{2} \mathrm{O}_{4}$, $\mathrm{Li}_{0.1} \mathrm{Zn}_{0.9} \mathrm{O}$, and composite samples are shown in Fig. 3. The grain size and the densities increased as the annealing temperature was increased. As shown in Fig. 4, densities of LZO+MFO samples increased as the annealing temperature increased due to the reduction of the number of pores, leading to densification at elevated temperatures.

$\mathrm{Li}_{0.1} \mathrm{Zn}_{0.9} \mathrm{O}$ added $\mathrm{MgFe}_{2} \mathrm{O}_{4}$ samples displayed soft magnetic behavior (Fig. 5). Magnetic properties were measured at room temperature in order to perform a detailed study and gain an insight into the magnetization phenomenon in the present samples. Magnetization decreased due to addition of $\mathrm{Li}_{0.1} \mathrm{Zn}_{0.9} \mathrm{O}$, which leads to an increase of the non magnetic phase and introduces pores, thus reducing the exchange interactions in the ferromagnetic phase (Fig. 5, 6), [14]. Since the magnetic material pre- 

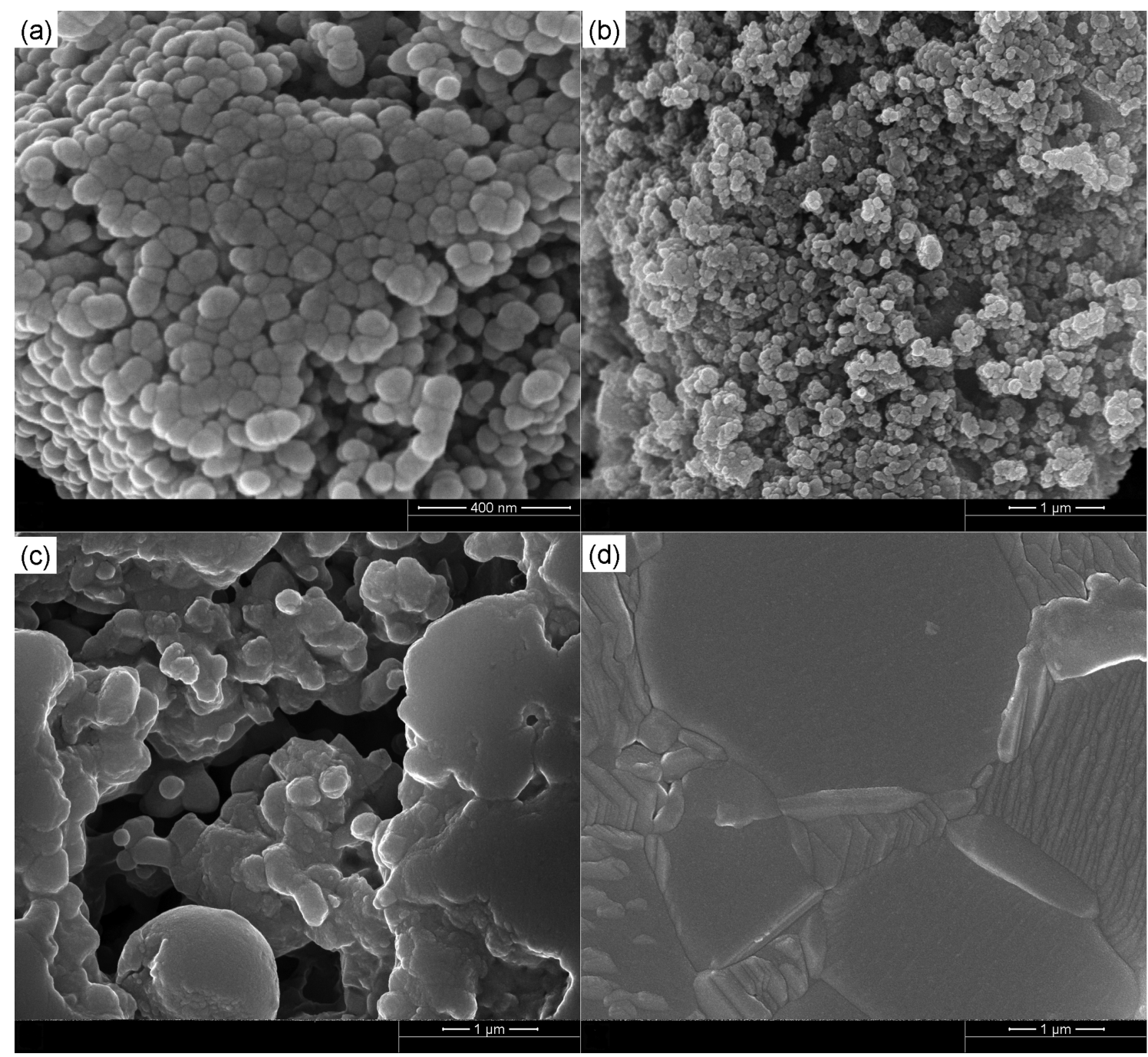

Fig. 3. SEM photographs of synthesized (a) $\mathrm{MgFe}_{2} \mathrm{O}_{4}$, (b) $\mathrm{Li}_{0.1} \mathrm{Zn}_{0.9} \mathrm{O}$, (c) and (d) $\mathrm{Li}_{0.1} \mathrm{Zn}_{0.9} \mathrm{O}+\mathrm{MgFe}_{2} \mathrm{O}_{4}$ thermally annealed at 900 and $1100^{\circ} \mathrm{C}$ for $1 \mathrm{~h}$.

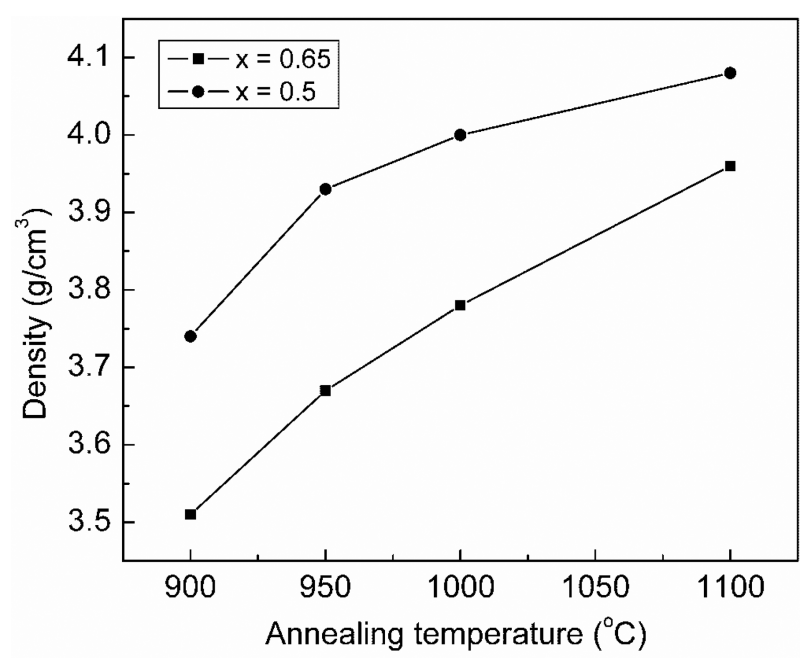

Fig. 4. Densities of $(1-x) \mathrm{Li}_{0.1} \mathrm{Zn}_{0.9} \mathrm{O}+(x) \mathrm{MgFe}_{2} \mathrm{O}_{4}[x=0.5,0.65]$ samples annealed for $1 \mathrm{~h}$.

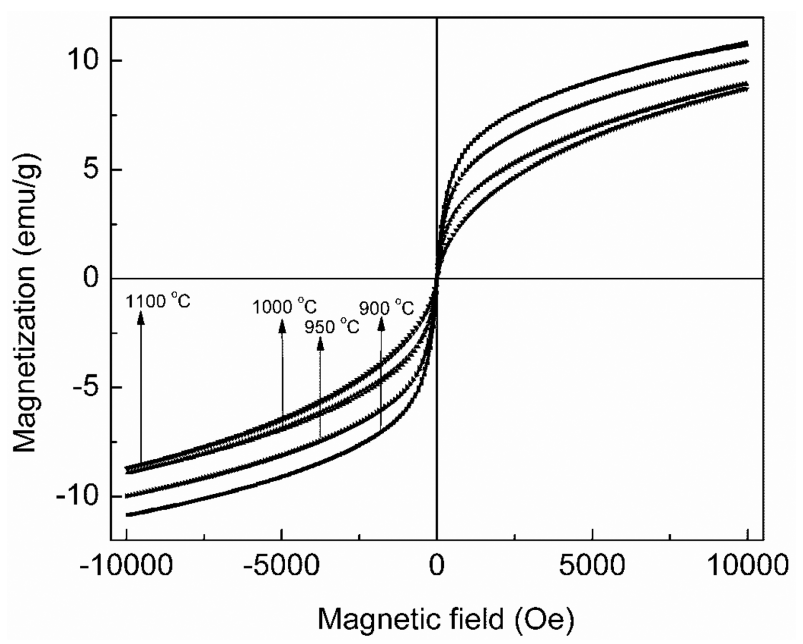

Fig. 5. Magnetization hysteresis loop measurements for $0.5 \mathrm{Li}_{0.1}$ $\mathrm{Zn}_{0.9} \mathrm{O}+0.5 \mathrm{MgFe}_{2} \mathrm{O}_{4}$ thermally annealed at 900 to $1100{ }^{\circ} \mathrm{C}$ for $1 \mathrm{~h}$. 


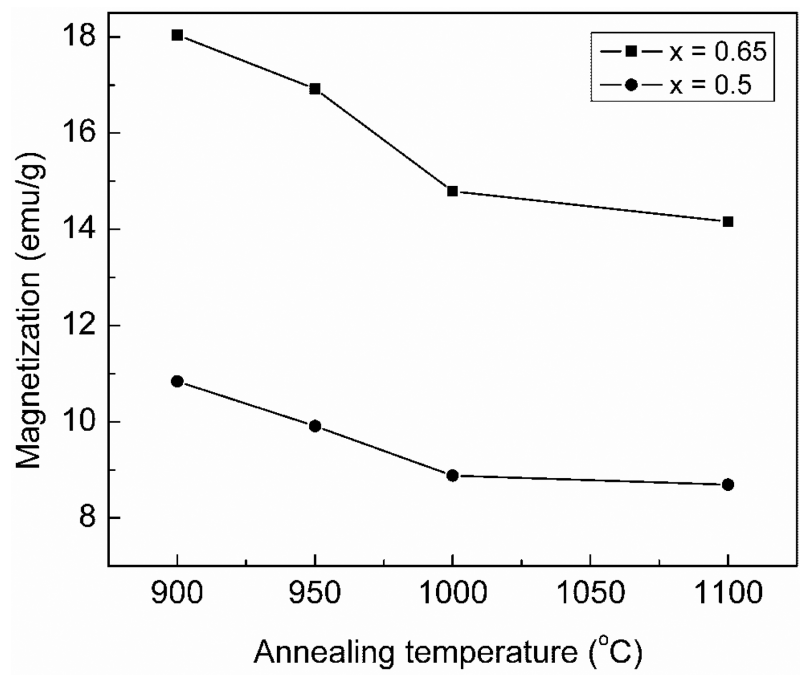

Fig. 6. Magnetization of $(1-x) \mathrm{Li}_{0.1} \mathrm{Zn}_{0.9} \mathrm{O}+(x) \mathrm{MgFe}_{2} \mathrm{O}_{4}[x=0.5$, $0.65]$ with respect to annealing temperature.

sent in the composites is of the inverse spinel type with polyhedral sites, variation of cations contributing to magnetization with respect to the annealing temperature was investigated in correlation with the structural changes occurring due to the annealing temperature via analysis of $\mathrm{X}$-ray diffraction patterns [12]. Migration of cations among tetrahedral and octahedral sites was calculated by comparison of intensities of diffraction peaks corresponding to tetrahedral and octahedral sites, as shown in Fig. 2. Ratios of $(220) /(222)$ peaks decreased as the annealing temperature increased, which is in accordance with the magnetization measurements as illustrated above.

\section{Conclusion}

$\mathrm{Li}_{0.1} \mathrm{Zn}_{0.9} \mathrm{O}+\mathrm{MgFe}_{2} \mathrm{O}_{4}$ samples exhibited soft magnetic behavior. $\mathrm{Li}_{0.1} \mathrm{Zn}_{0.9} \mathrm{O}$ was found to have an influence on the magnetization behavior of the $\mathrm{Li}_{0.1} \mathrm{Zn}_{0.9} \mathrm{O}+\mathrm{MgFe}_{2} \mathrm{O}_{4}$ samples. Variation of cations in tetrahedral and octahedral sites could be calculated by comparison of $(220) /(222)$ peak intensities in the X-ray diffraction data. This procedure can be adopted to investigate the magnetization phenomena in materials with spinel structures with simplicity.

\section{Acknowledgement}

This research was supported by a grant (06K140100920) from the Centre for Nanoscale Mechatronics and Manufacturing, a $21^{\text {st }}$ Century Frontier Research Program.

\section{References}

[1] W. Eerenstein, N. D. Mathur, and J. F. Scott, Nature 442, 759 (2006).

[2] S. W Sheongi and M. Mostovoy, Nat. Mat. 6, 13 (2007).

[3] A. Singh, V. Pandey, R. K. Kotnala, and D. Pandey, Phys. Rev. Lett. 101, 247602 (2008).

[4] S. Priya, R. Islam, S. Dong, and D. Viehland, J. Electroceram. 19, 147 (2007).

[5] M. Fiebig, J. Phys. D 38, R123 (2005).

[6] N. A. Spaldin and M. Fiebig, Science 309, 391 (2005).

[7] R. Tadi, Y. I. Kim, A. K. Sarella, C. G. Kim, and K. S. Ryu, J. Magn. Magn. Mater. 322, 3372 (2010).

[8] M. Gateshki, V. Petkov, S. K. Pradhan, and T. Vogt, J. Appl. Cryst. 38, 772 (2005).

[9] Z. L. Wang, J. Phys.: Cond. Matt. 16, R829 (2004).

[10] A. Onodera, N. Tamaki, Y. Kawamura, T. Sawada, and H. Yamashita, Jpn. J. Appl. Phys. 35, 5160 (1996).

[11] H. K. Yadav, K. Sreenivas, V. Gupta, and R. S. Katiyar, J. Appl. Phys. 104, 053507 (2008).

[12] V. Sepelak, D. Baabe, D. Mienert, D. Schultze, F. Krumeich, F. J. Litterst, and K. D. Becker, J. Magn. Magn. Mater. 257, 377 (2003).

[13] S. Chitra, P. Kalyani, B. Yebka, T. Mohan, E. H. Poniatowski, R. Gangadharana, and C. Julien, Mater. Chem. Phys. 65, 32 (2000).

[14] C. M. Kanamadi, J. S. Kim, H. K. Yang, B. K. Moon, B. C. Choi, and J. H. Jeong, Appl. Phys. A 97, 575 (2009). 